Supporting Information

\title{
Three-Dimensional (3D) Nanostructured Skeleton Substrate Composed of Hollow Carbon Fiber/Carbon Nanosheet/ZnO for Stable Lithium Anode
}

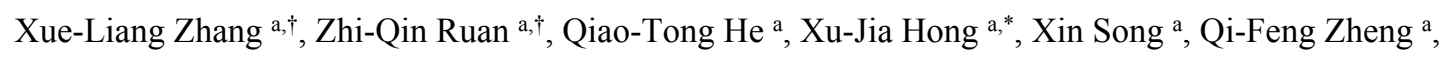
Jia-Hui Nie a , Yue-Peng Cai a, ${ }^{*}$ and Hongxia Wang b,*

${ }^{a}$ School of Chemistry, South China Normal University, Guangzhou, 510006, China

${ }^{b}$ School of Chemistry and Physics, Queensland University of Technology(QUT), Brisbane, QLD 4001, Australia.

Corresponding author E-mail: hxuscnu@m.scnu.edu.cn (Xu-Jia Hong); caiyp@scnu.edu.cn (Yue-Peng Cai); hx.wang@qut.edu.au (Hongxia Wang) 


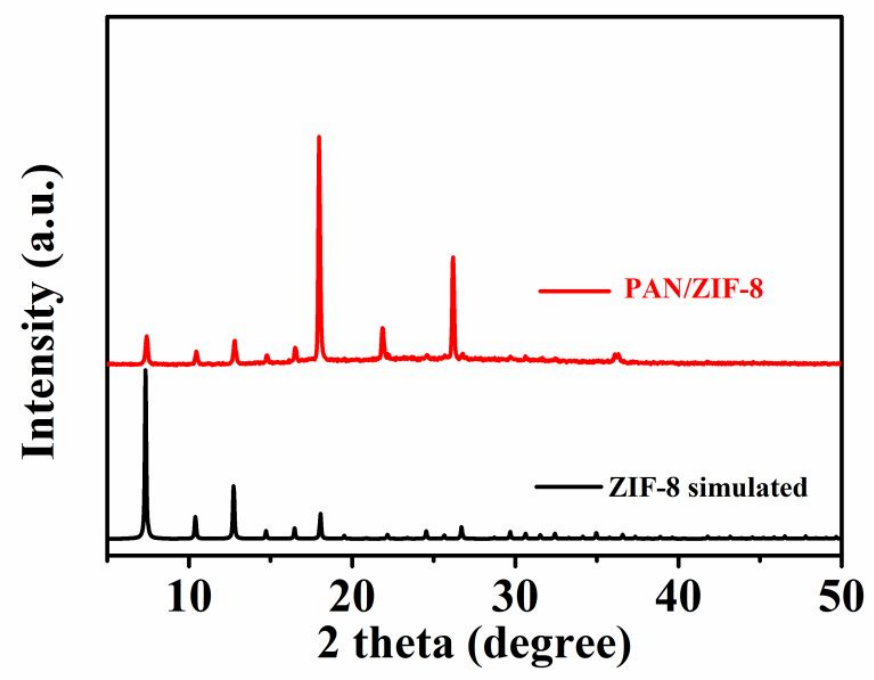

Figure S1. XRD pattern of PAN/ZIF-8.

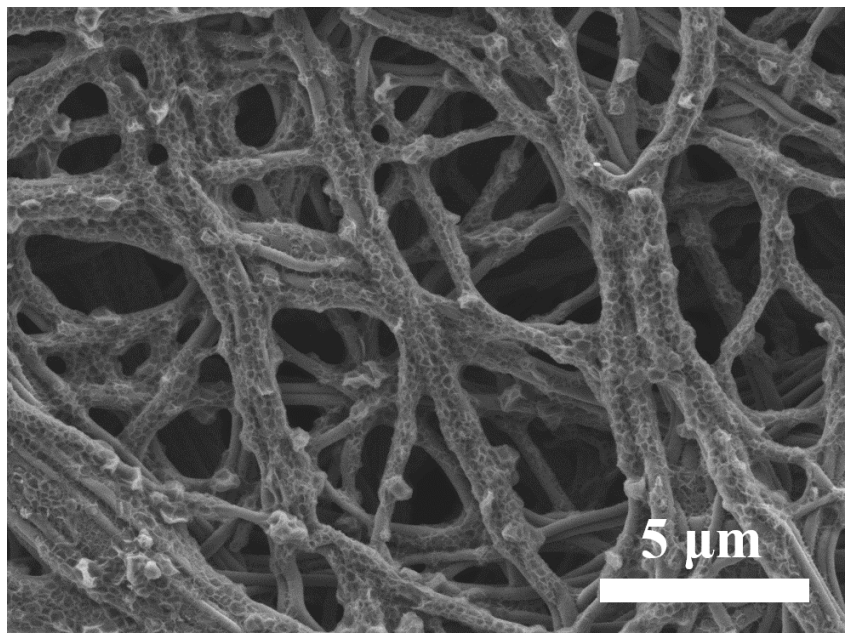

Figure S2. SEM image of $\mathrm{NHCF} / \mathrm{CN} / \mathrm{ZnO}$.
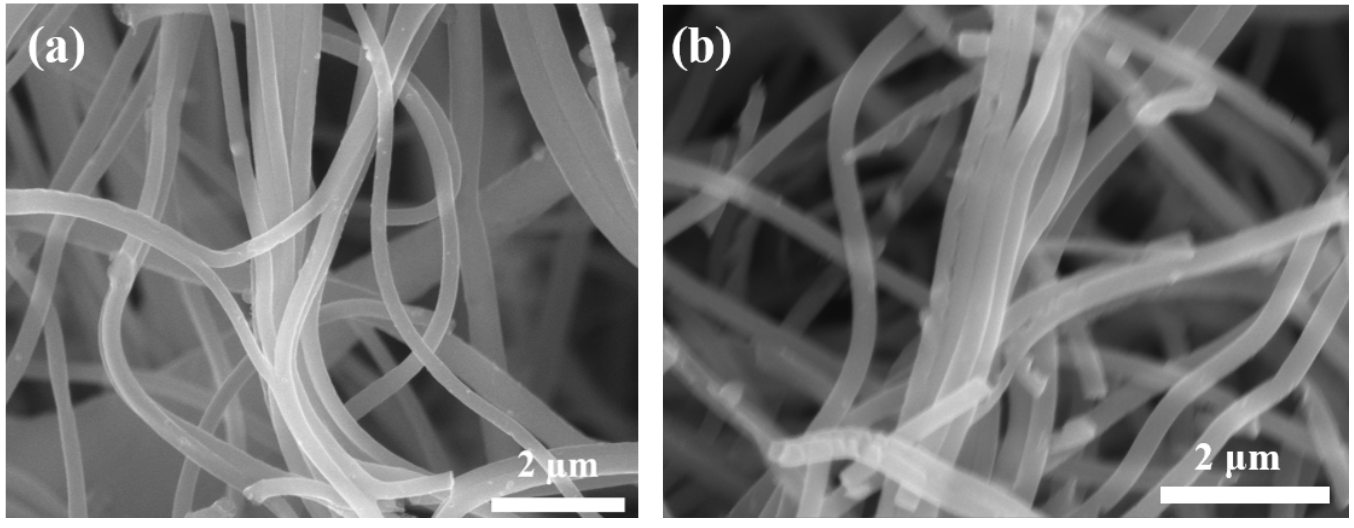

Figure S3. SEM images of (a) NCF and (b) NHC. 

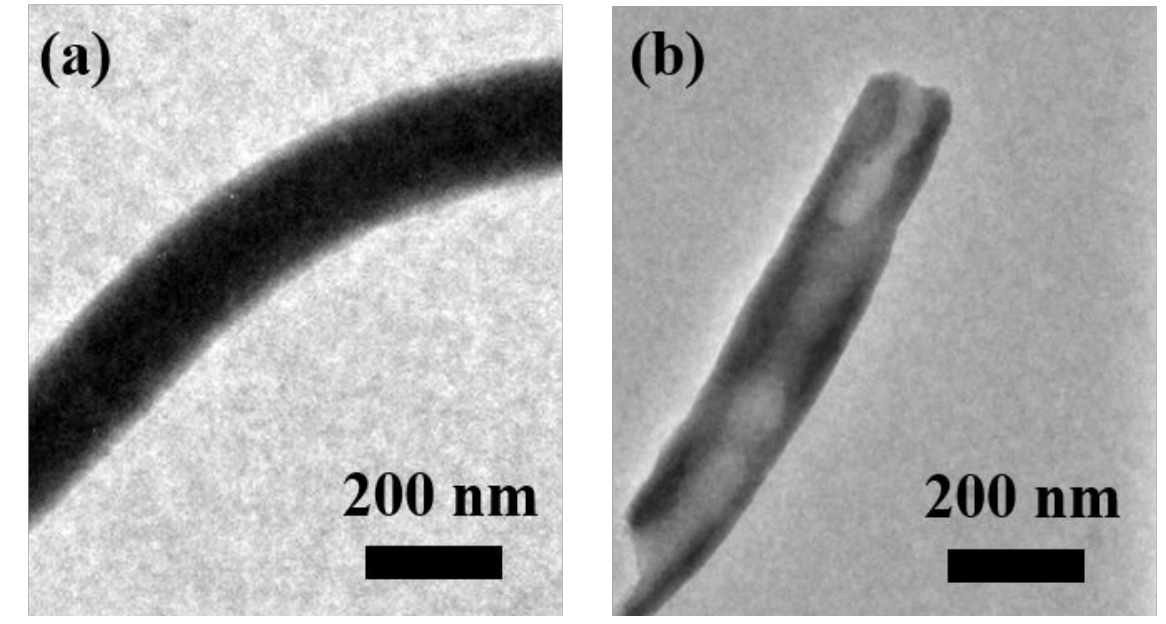

Figure S4. TEM images of (a) NCF and (b) NHC.

(a)

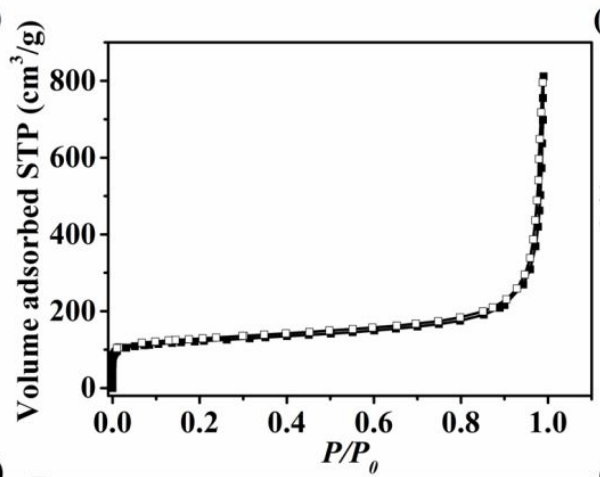

(c)

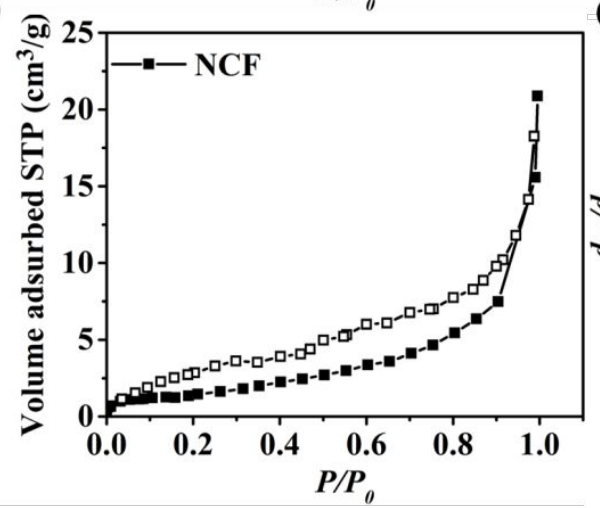

(b)

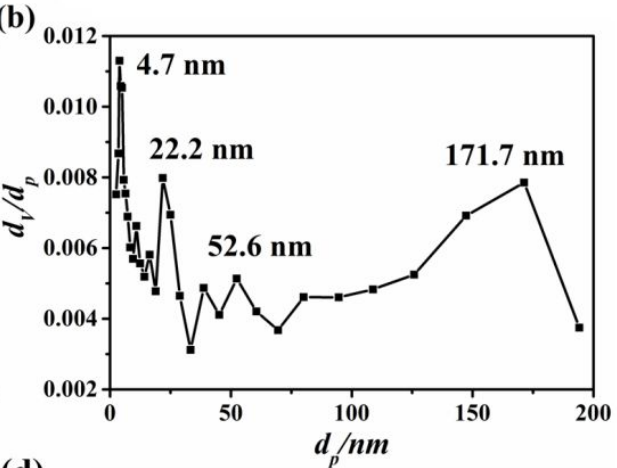

(d)

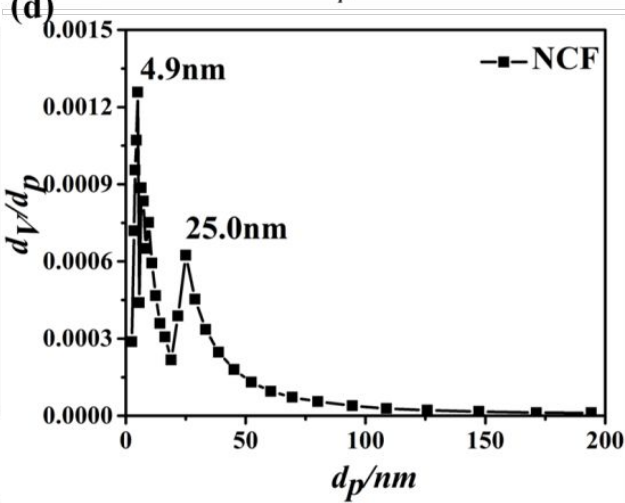

Figure S5. The $\mathrm{N}_{2}$ adsorption curves of (a) $\mathrm{NHCF} / \mathrm{CN} / \mathrm{ZnO}$ and (c) NCF, the corresponding pore size distribution curves of (b) $\mathrm{NHCF} / \mathrm{CN} / \mathrm{ZnO}$ and (d) NCF. 

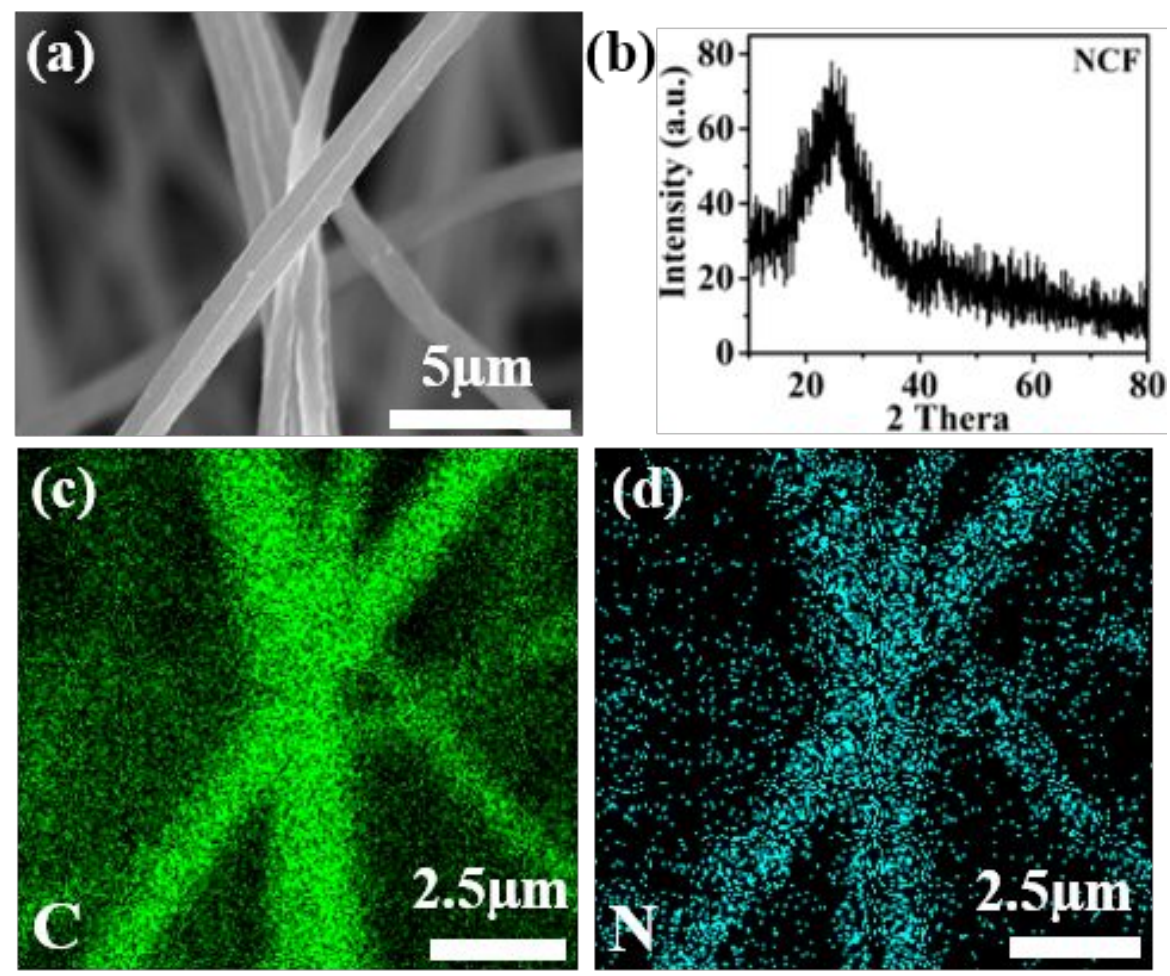

Figure S6 (a) SEM image of NCF, (b) XRD pattern of NCF, (c-d) EDS mapping images of NCF.
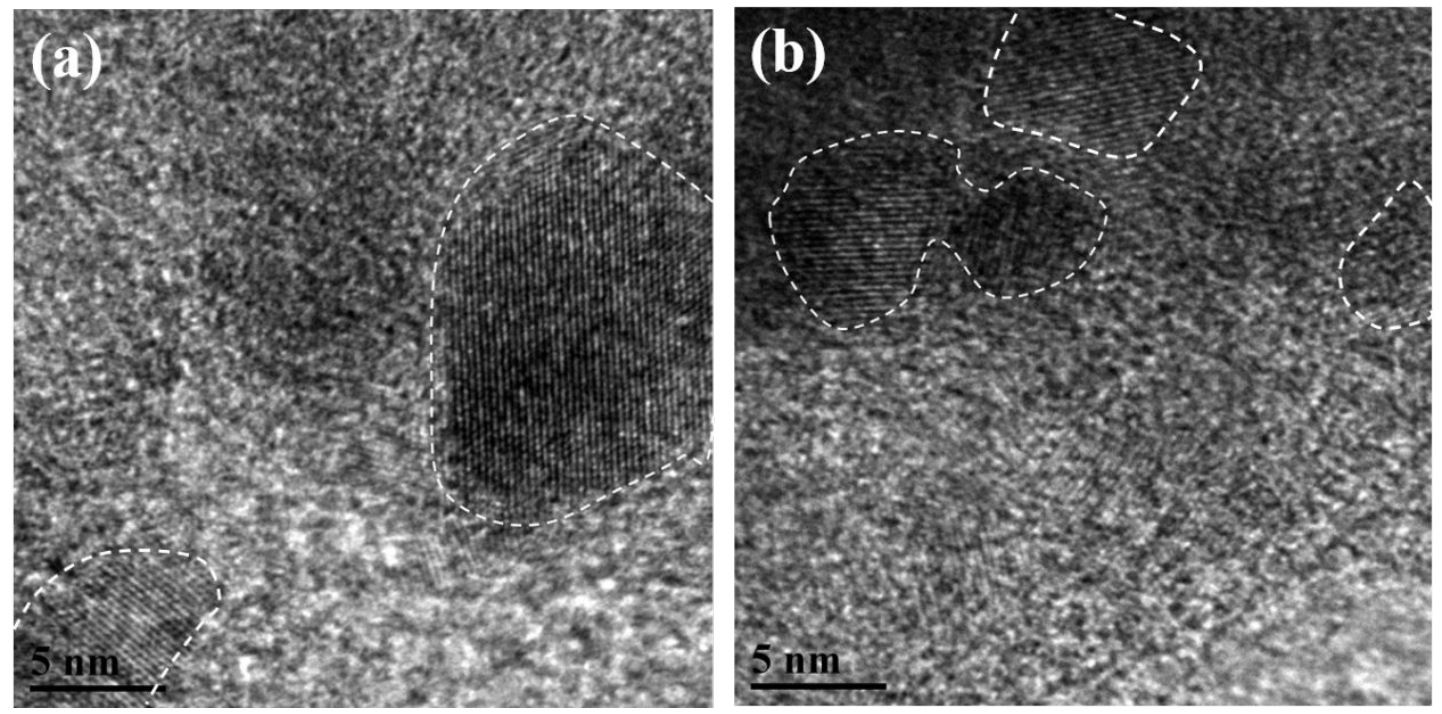

Figure S7. TEM images of the nanosheet on $\mathrm{NHCF} / \mathrm{CN} / \mathrm{ZnO}$ ( the nanoparticles in the white circle are zinc oxide crystals). 
(a)

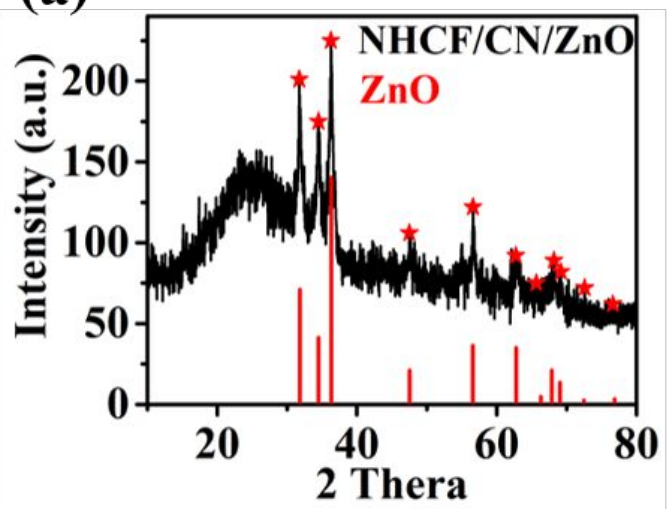

(c)

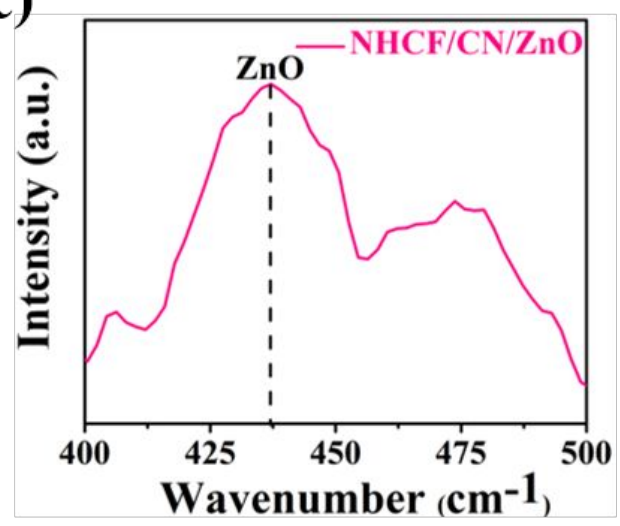

(b)

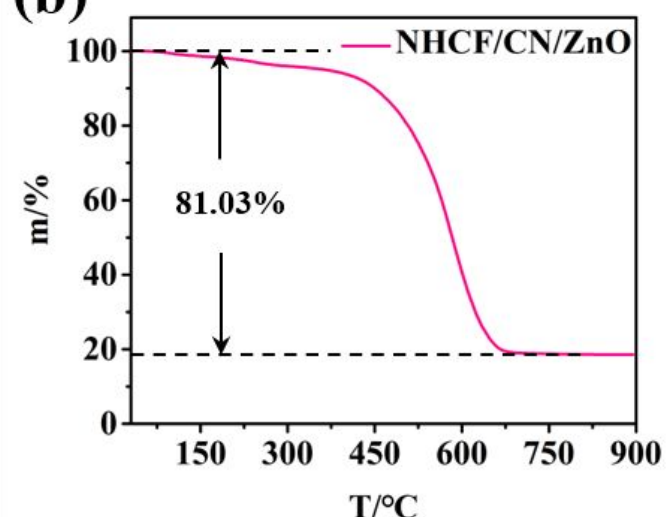

(d)

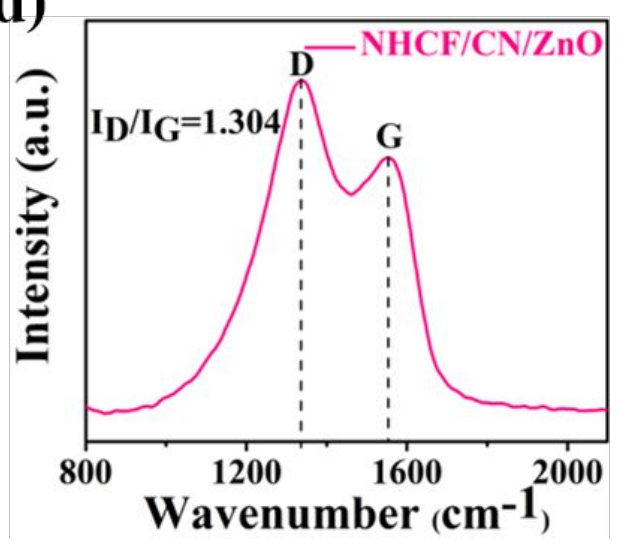

Figure S8. (a) XRD pattern of $\mathrm{NHCF} / \mathrm{CN} / \mathrm{ZnO}$. (b) Thermogravimetric analysis of $\mathrm{NHCF} / \mathrm{CN} / \mathrm{ZnO}$. (c,d) Reman spectroscopy of the sample.
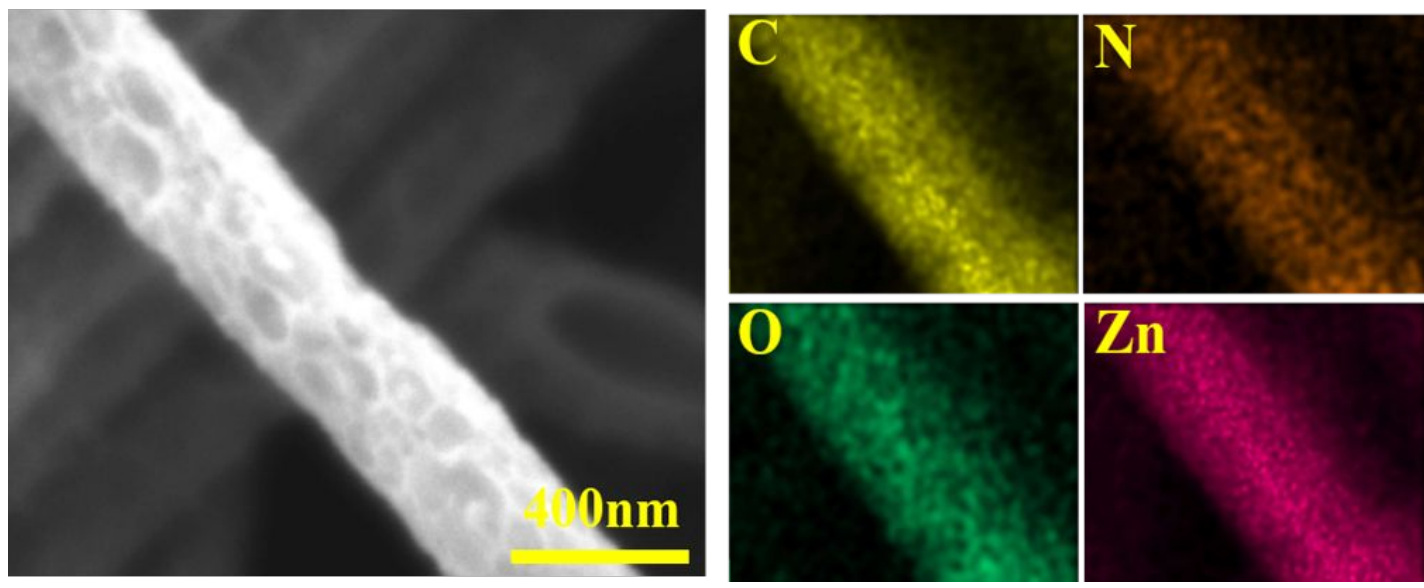

Figure S9. EDS mapping of $\mathrm{NHCF} / \mathrm{CN} / \mathrm{ZnO}$. 
(a)

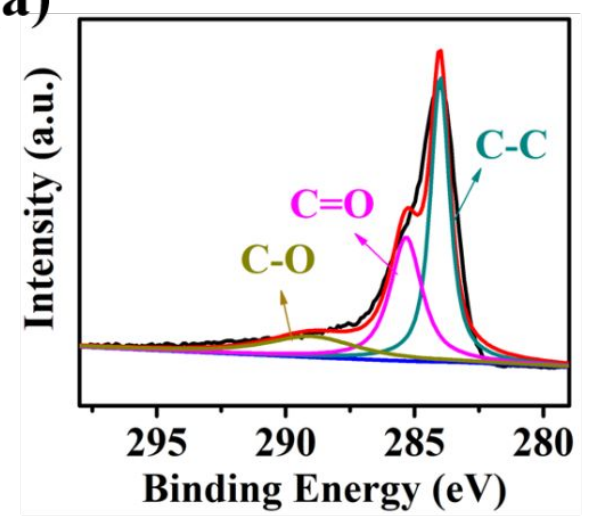

(c)

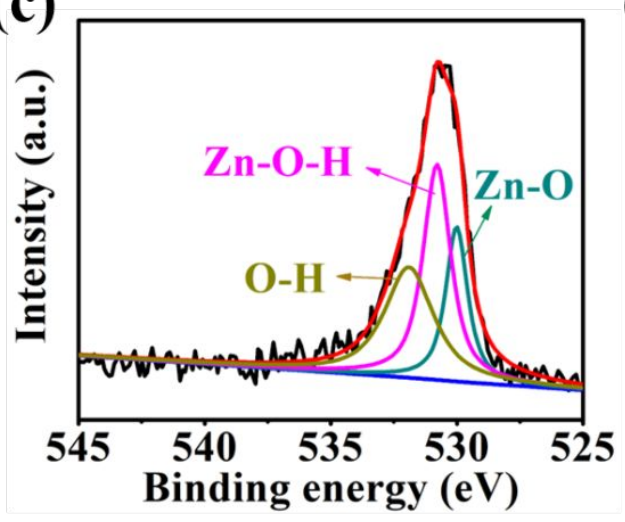

(b)

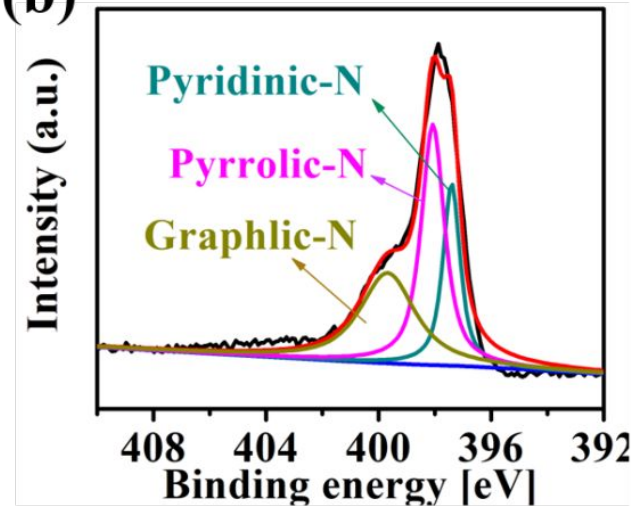

(d)

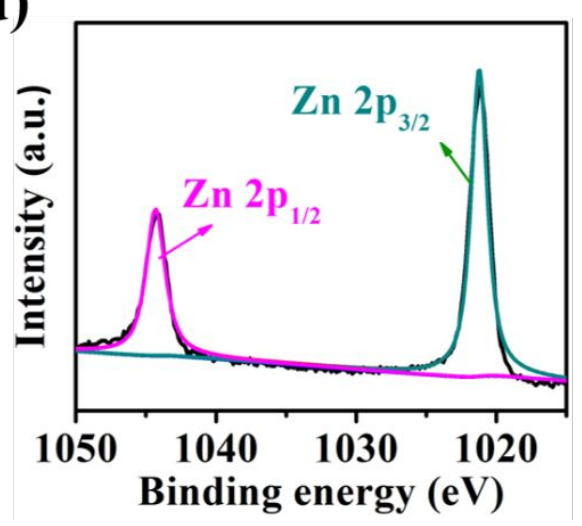

Figure S10. XPS spectrum of NHCF/CN/ZnO. (a) C 1s XPS spectra, (b) N 1s XPS spectra, (c) O 1s XPS spectra, (d) Zn 2p XPS spectra.

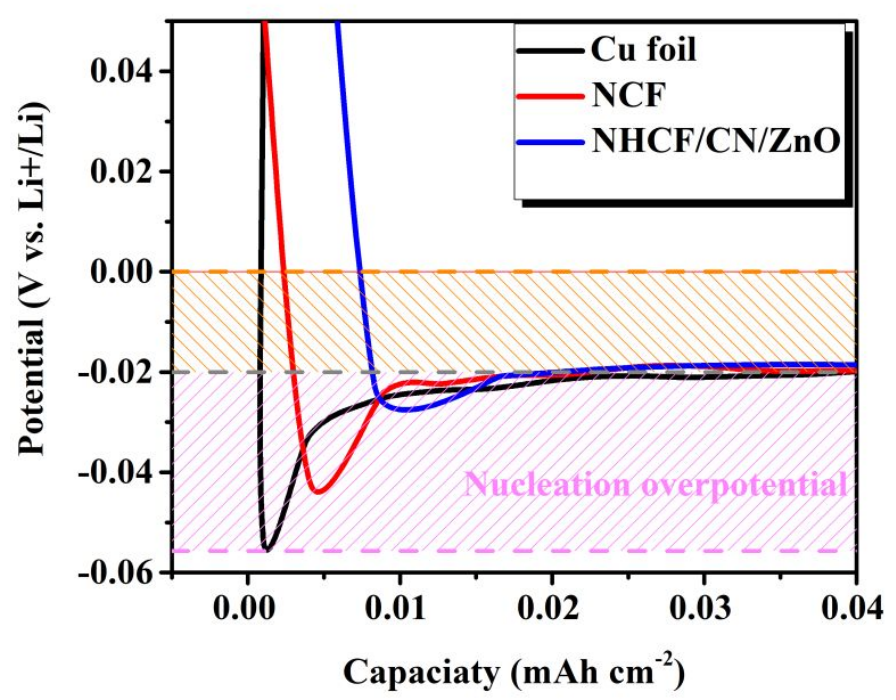

Figure S11. The voltage profiles of $\mathrm{NHCF} / \mathrm{CN} / \mathrm{ZnO}, \mathrm{NCF}$ and $\mathrm{Cu}$ foil during the $\mathrm{Li}$ plating at $0.5 \mathrm{~mA} \mathrm{~cm}^{-2}$. 

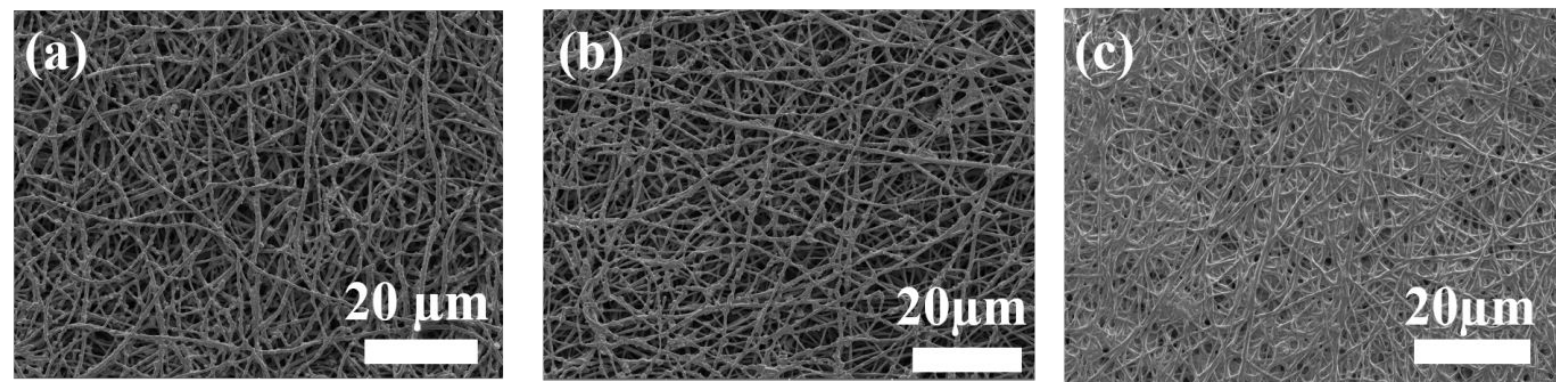

Figure S12. SEM images of $\mathrm{NHCF} / \mathrm{CN} / \mathrm{ZnO}$ with different amount of deposited Li :

(a) $1 \mathrm{mAh} \mathrm{cm}^{-2}$, (b) $3 \mathrm{mAh} \mathrm{cm}^{-2}$, (c) $5 \mathrm{mAh} \mathrm{cm}^{-2}$.
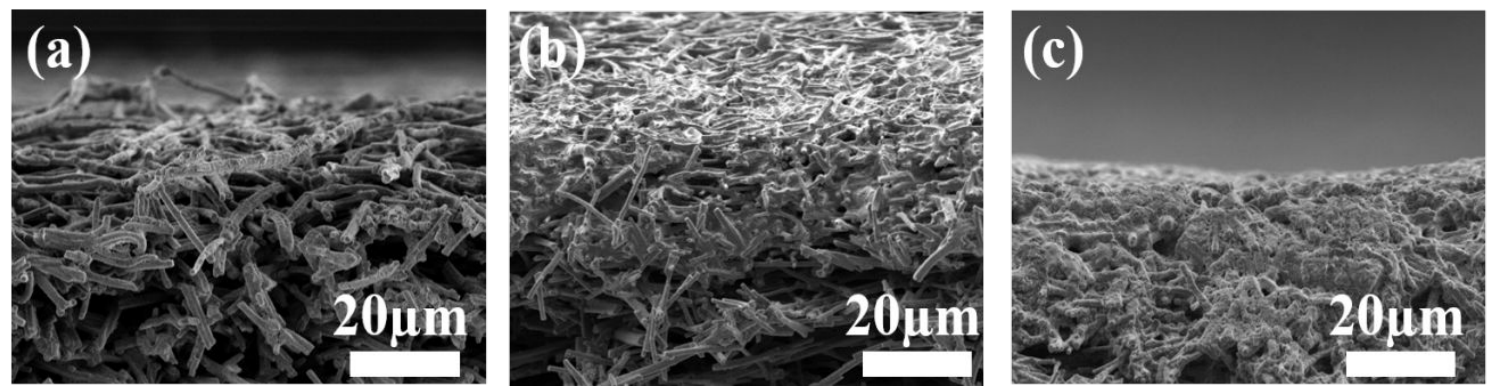

Figure S13. Sectional SEM images of $\mathrm{NHCF} / \mathrm{CN} / \mathrm{ZnO}$ with different amount of deposited Li : (a) $1 \mathrm{mAh} \mathrm{cm}^{-2}$, (b) $3 \mathrm{mAh} \mathrm{cm}^{-2}$, (c) $5 \mathrm{mAh} \mathrm{cm}^{-2}$.
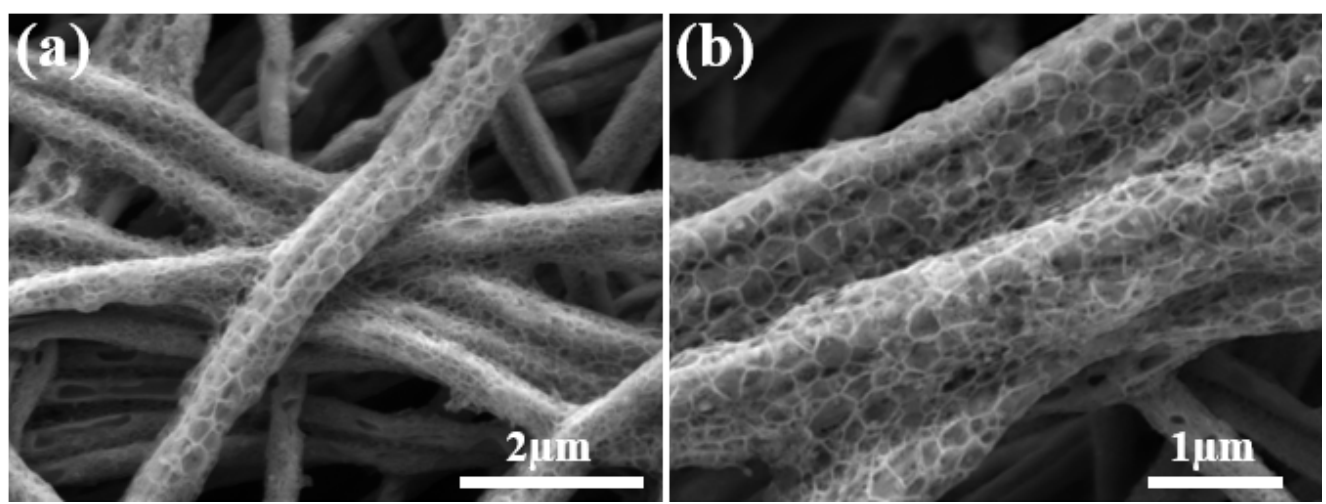

Figure S14. The SEM image of the electrode after removing the pre-deposited lithium. 


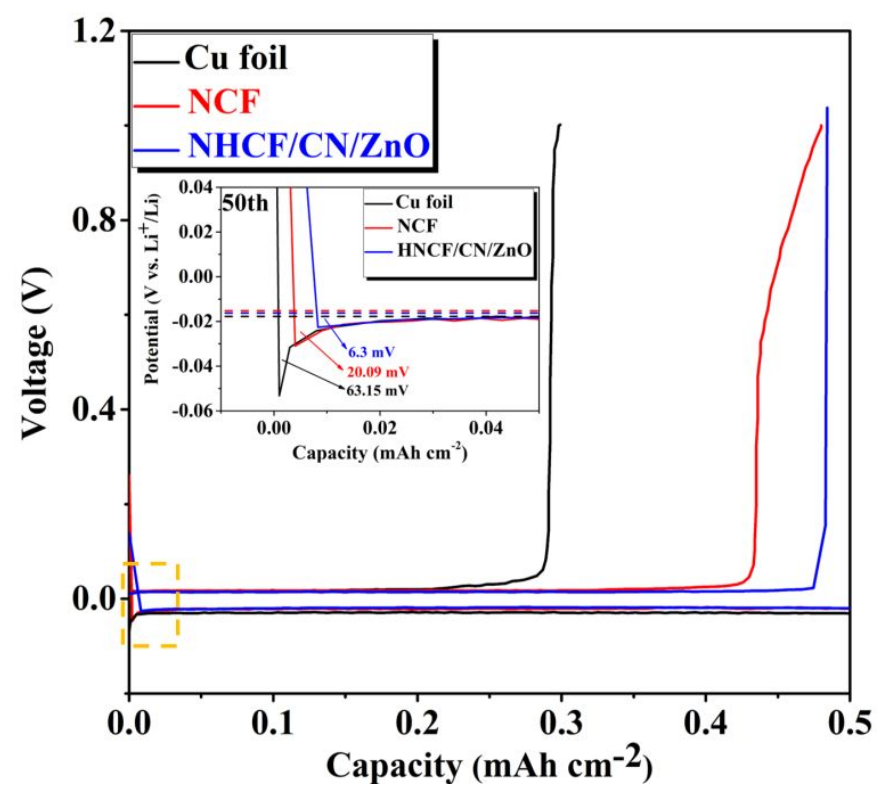

Figure S15. The voltage profiles of $\mathrm{NHCF} / \mathrm{CN} / \mathrm{ZnO}, \mathrm{NCF}$ and $\mathrm{Cu}$ foil after $50^{\text {th }}$ cycle at $0.5 \mathrm{mAh} \mathrm{cm}^{-2}, 0.5 \mathrm{~mA} \mathrm{~cm}^{-2}$, and the inside picture is the partial magnification of the

voltage profiles of $\mathrm{NHCF} / \mathrm{CN} / \mathrm{ZnO}$.

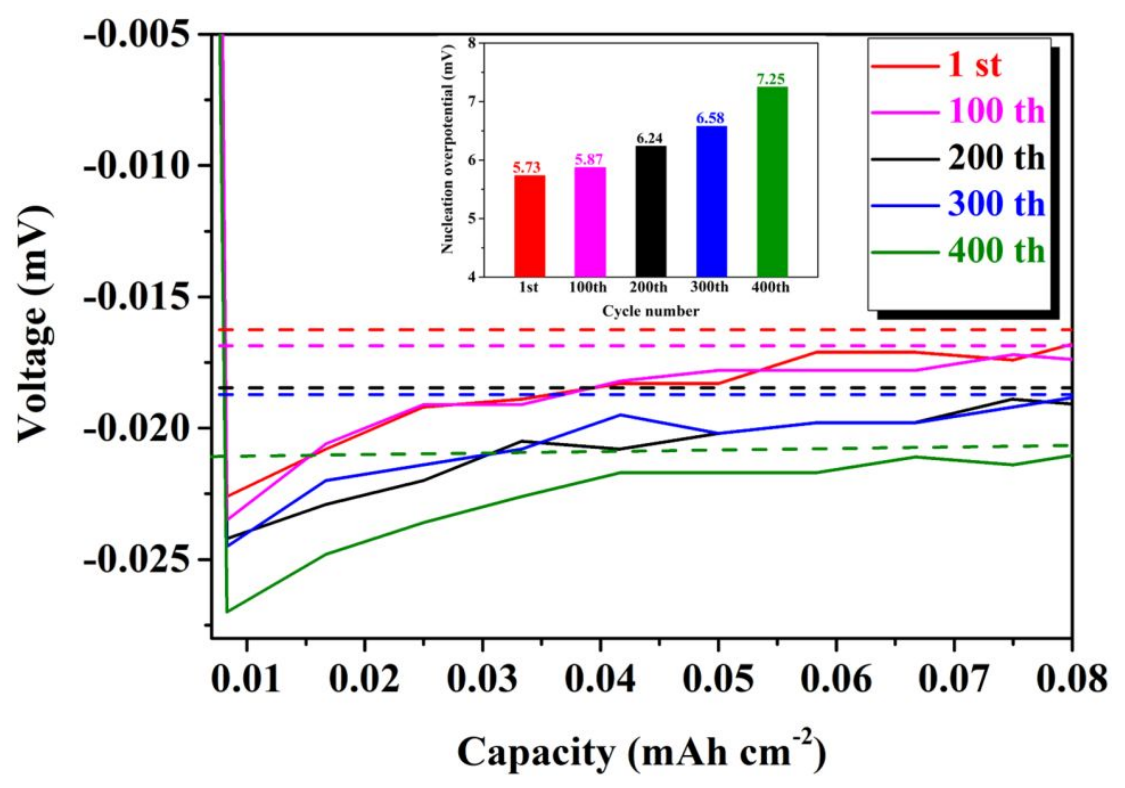

Figure S16. The voltage profiles of $\mathrm{NHCF} / \mathrm{CN} / \mathrm{ZnO}$ current collector after $1^{\text {st }}, 100^{\text {th }}$, $200^{\text {th }}, 300^{\text {th }}, 400^{\text {th }}$ at $0.5 \mathrm{mAh} \mathrm{cm}^{-2}$ with $0.5 \mathrm{~mA} \mathrm{~cm}^{-2}$, and the inside picture is the distribution of nucleation overpotential of $\mathrm{NHCF} / \mathrm{CN} / \mathrm{ZnO}$. 

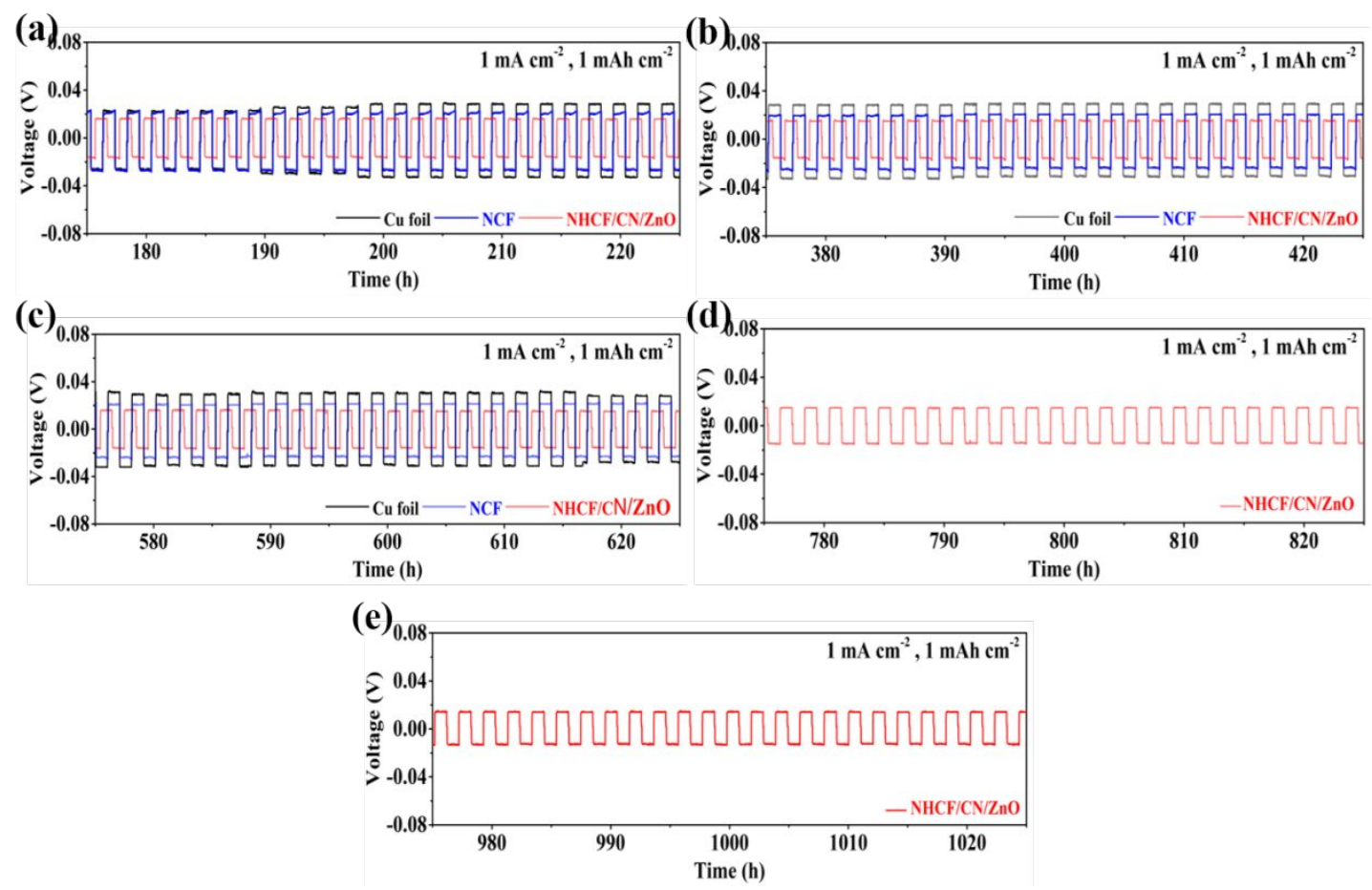

Figure S17. The enlarged voltage curves of the symmetric cells with three electrodes at $1 \mathrm{~mA} \mathrm{~cm}^{-2}$ and $1 \mathrm{mAh} \mathrm{cm}^{-2}$.
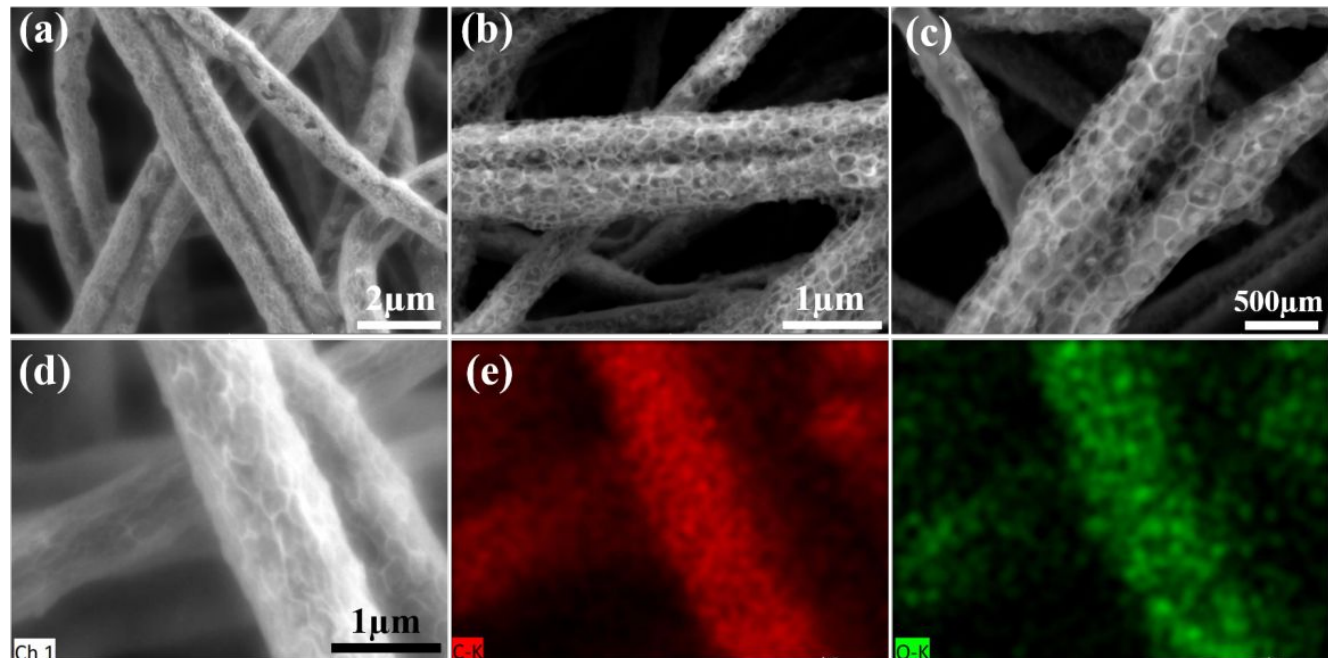

(e)
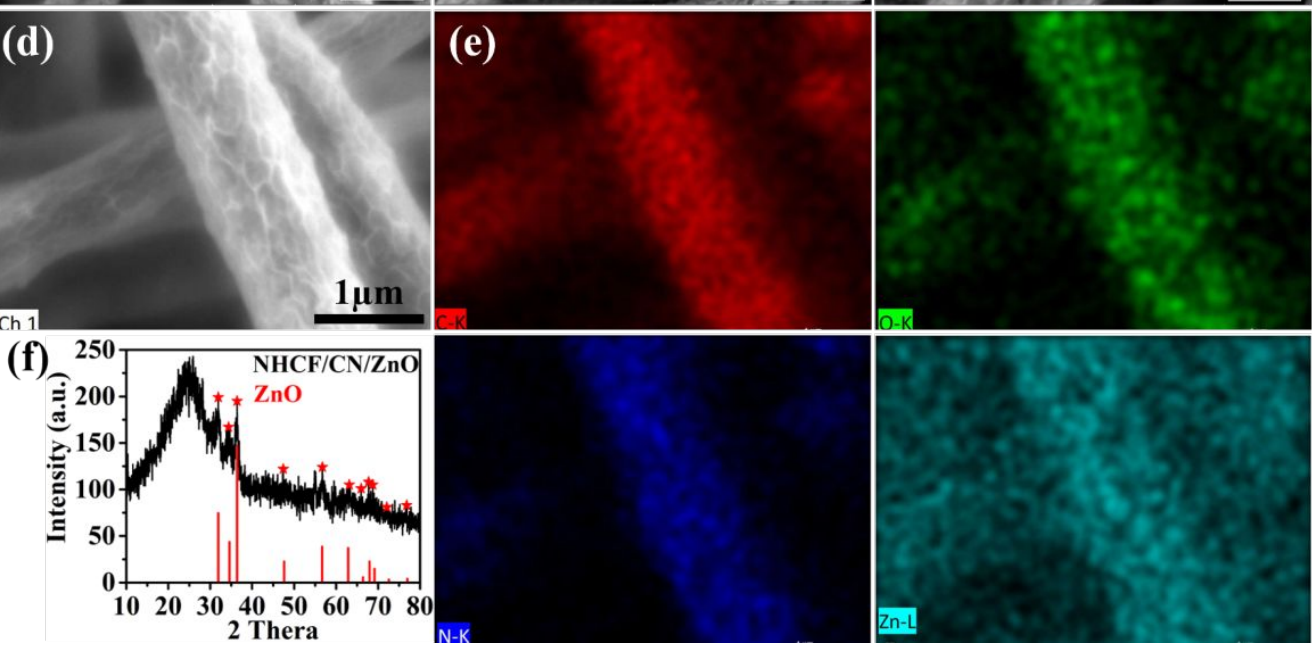

Figure S18. Characterization data of $\mathrm{NHCF} / \mathrm{CN} / \mathrm{ZnO}$ after 500 cycles at $1 \mathrm{mAh} \mathrm{cm}^{-2}$ $1 \mathrm{~mA} \mathrm{~cm}^{-2}$. (a-d) SEM, (e) EDS mapping, and (f) XRD images of the sample. 

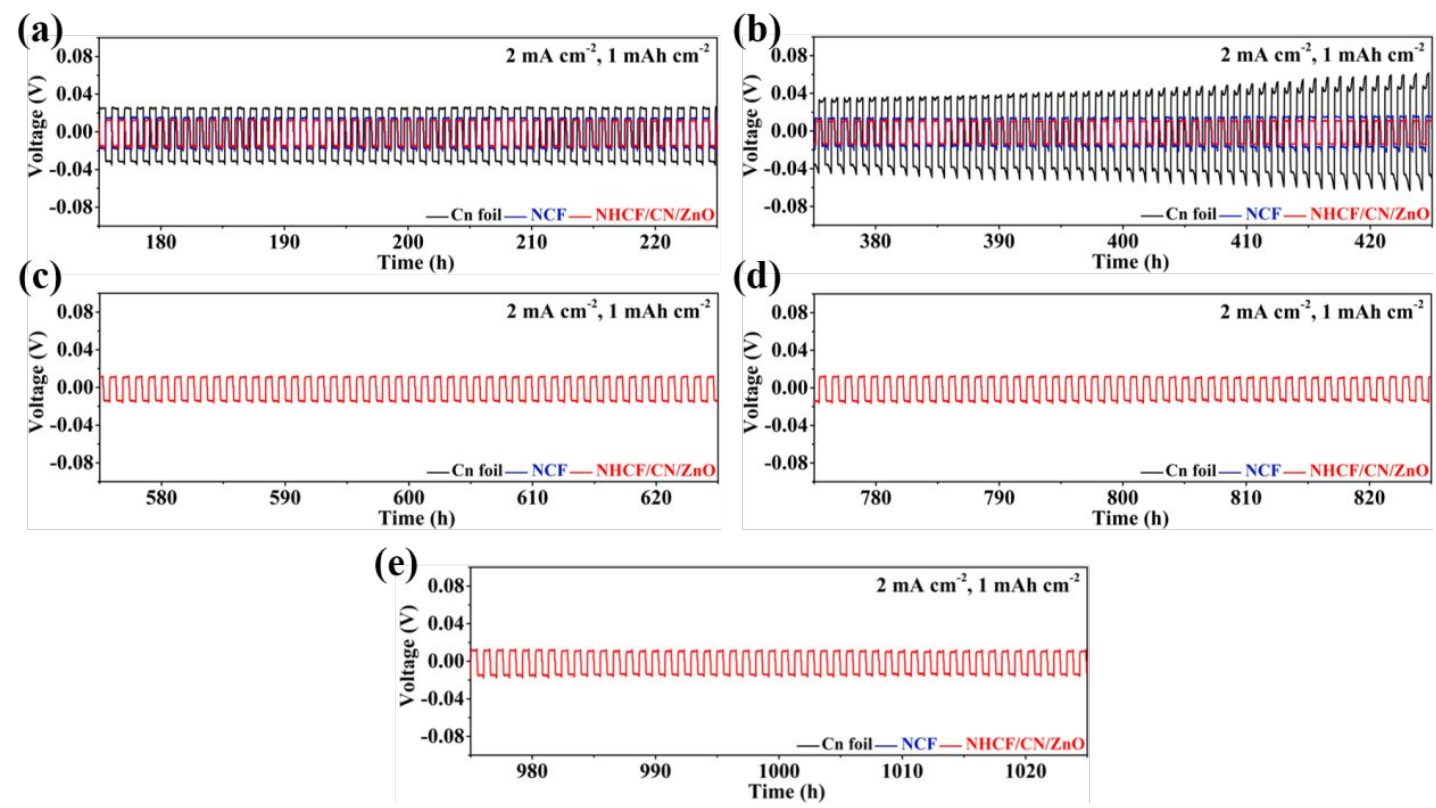

Figure S19. The enlarged voltage curves of the symmetric cells with three electrodes at $2 \mathrm{~mA} \mathrm{~cm}^{-2}$ and $1 \mathrm{mAh} \mathrm{cm}^{-2}$.

(a)

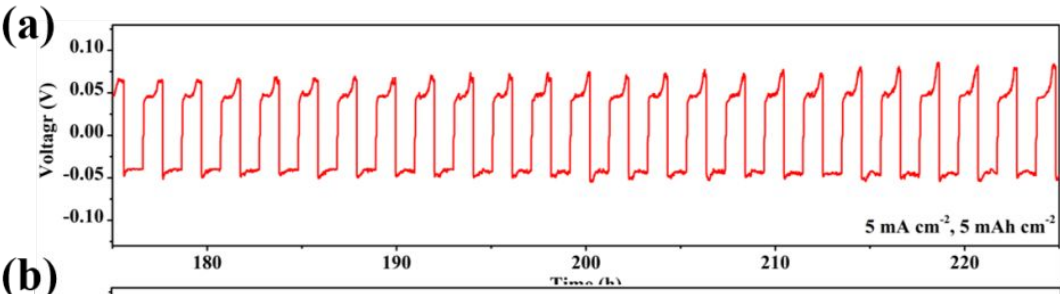

(b)

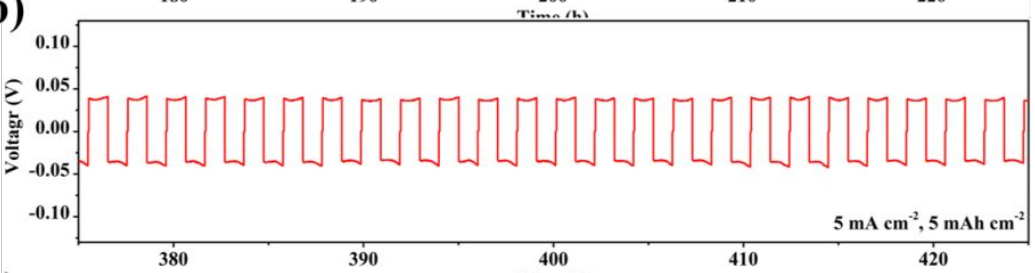

(c)

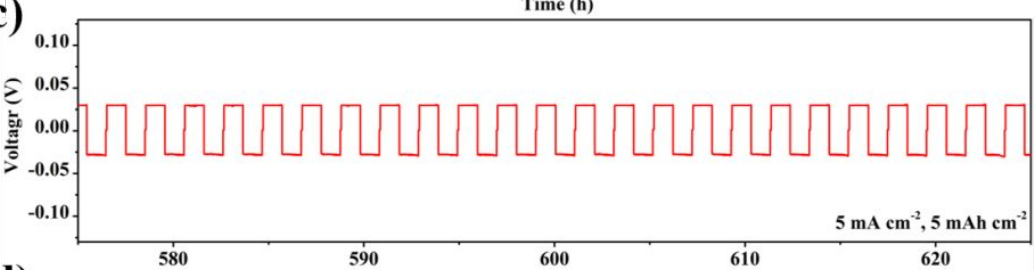

(d)

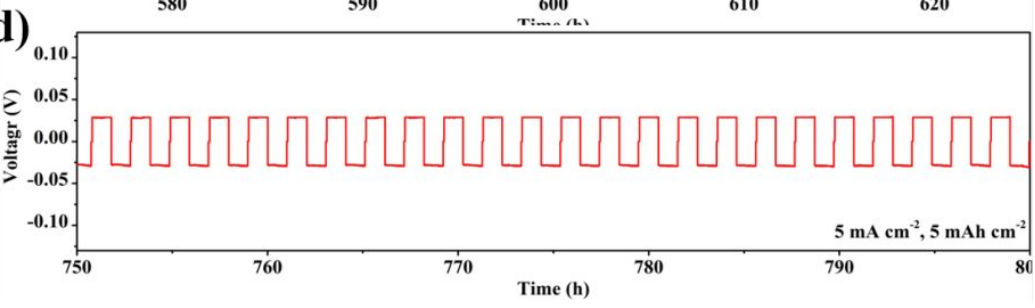

Figure S20. The enlarged voltage curves of the symmetric cells with three electrodes at $5 \mathrm{~mA} \mathrm{~cm}^{-2}$ and $5 \mathrm{mAh} \mathrm{cm}^{-2}$. 


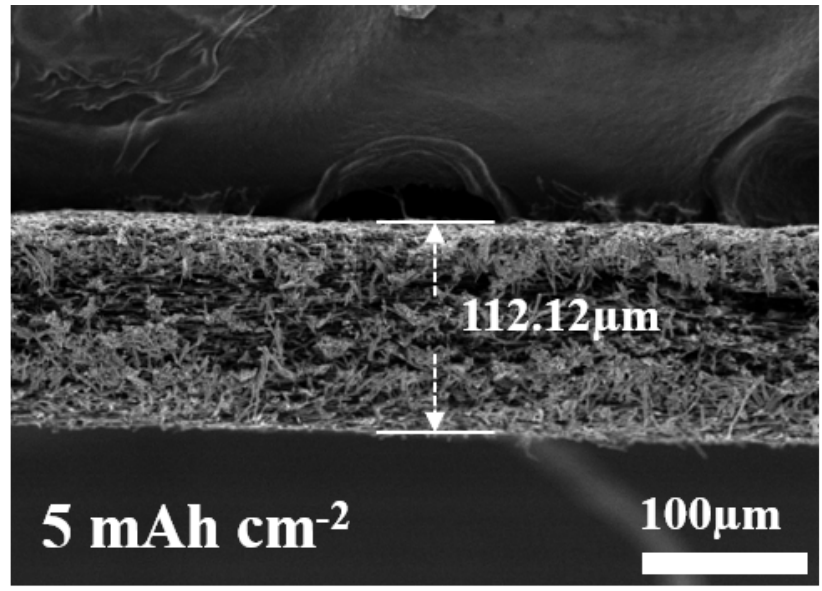

Figure S21. The side view of $\mathrm{NHCF} / \mathrm{CN} / \mathrm{ZnO} / \mathrm{Li}$ with the pre-deposited $\mathrm{Li}$ of $5 \mathrm{mAh}$ $\mathrm{cm}^{-2}$.

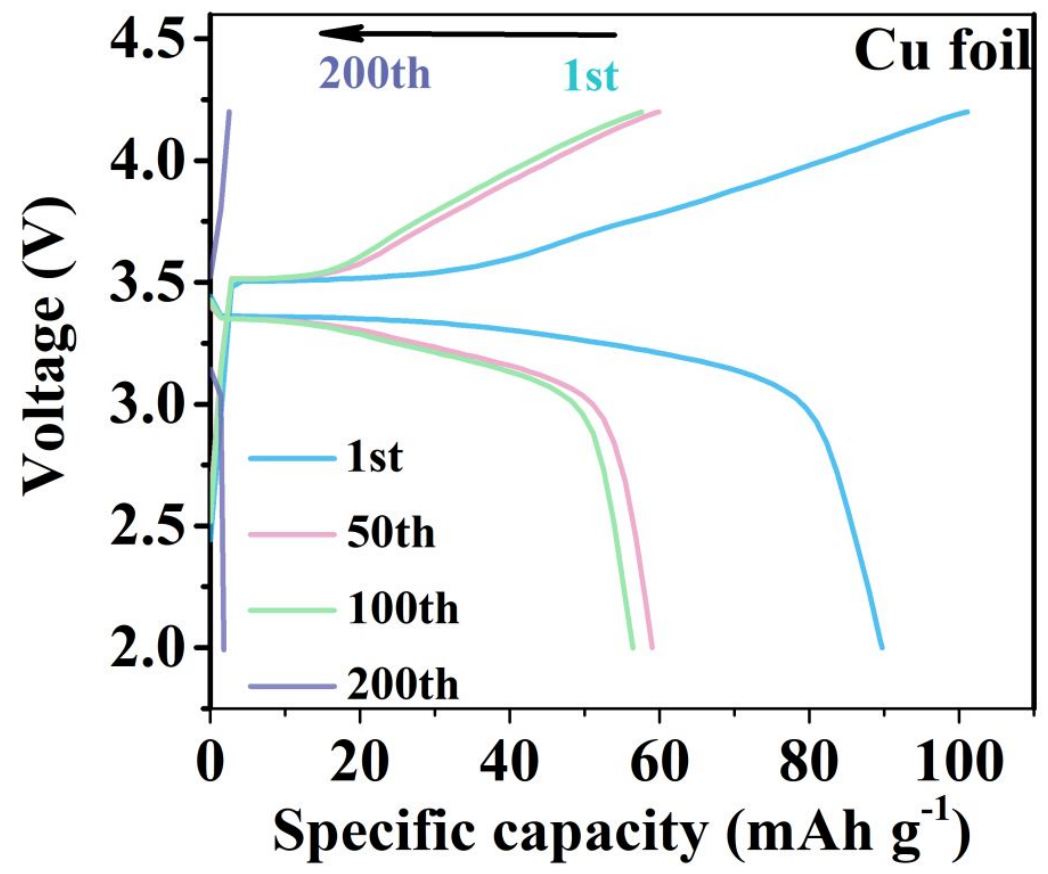

Figure S22. The change/dischange profile of the full cell with $\mathrm{LiFePO}_{4}$ as the cathode and the $\mathrm{Cu}$ foil as the anode at $0.5 \mathrm{C}$. 


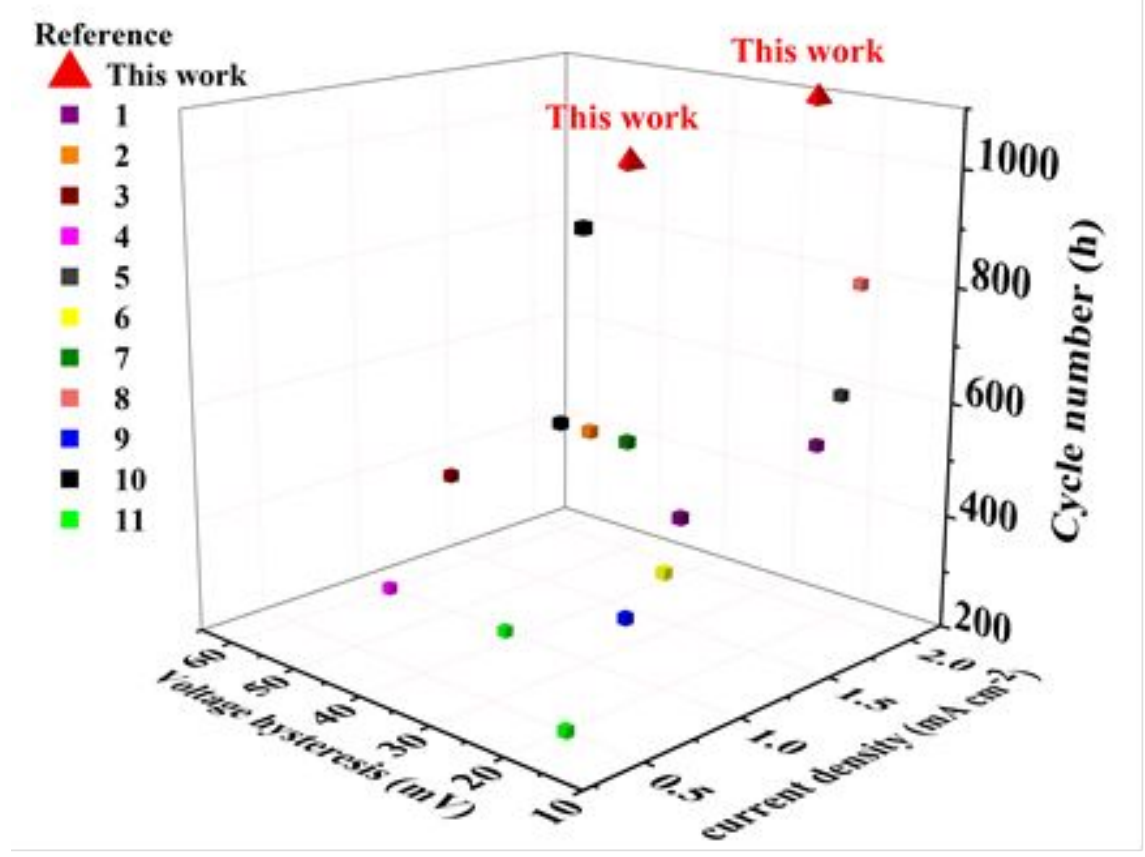

Figure S23. The electrochemical performance of $\mathrm{NHCF} / \mathrm{CN} / \mathrm{ZnO} / \mathrm{Li} \mid \mathrm{Li}$ cell is compared with different symmetrical cells at the same capacity of $1 \mathrm{mAh} \mathrm{cm}{ }^{-2}$

Table S1. The value of Rs and $\mathrm{R}_{1}$ of $\mathrm{Li}$ symmetrical cells at different cycles.

\begin{tabular}{|c|c|c|c|c|c|c|c|c|c|}
\hline & \multicolumn{3}{|c|}{ NHCF/CN/ZnO } & \multicolumn{3}{|c|}{ NCF } & \multicolumn{3}{c|}{ Cu foil } \\
\hline $\begin{array}{c}\text { Cycle } \\
\text { number }\end{array}$ & 1 th & 10 th & 50 th & 1 th & 10 th & 50 th & 1 th & 10 th & 50 th \\
\hline Rs/Ohm & 4.325 & 4.329 & 5.164 & 2.619 & 2.602 & 2.106 & 1.669 & 1.656 & 2.328 \\
\hline$R_{1} /$ Ohm & 95.92 & 46.36 & 13.56 & 106.21 & 85.25 & 24.55 & 320.8 & 139.15 & 89.05 \\
\hline
\end{tabular}


Table S2. Comparison of Li symmetric cells based on 3D anodes.

\begin{tabular}{|c|c|c|c|c|c|c|}
\hline $\begin{array}{l}\text { Structure type of } \\
\text { current collector }\end{array}$ & $\begin{array}{c}\text { Lithium } \\
\text { symmetric cell }\end{array}$ & $\begin{array}{c}\text { Current } \\
\text { density } \\
\left(\mathrm{mA} \mathrm{cm}^{-2}\right)\end{array}$ & $\begin{array}{c}\text { Capacity } \\
(\mathrm{mAh} \\
\left.\mathrm{cm}^{-2}\right)\end{array}$ & $\begin{array}{c}\text { Cycle } \\
\text { number } \\
\text { (h) }\end{array}$ & $\begin{array}{c}\text { Voltage } \\
\text { Hysteresis } \\
(\mathrm{mV})\end{array}$ & Reference \\
\hline \multirow[b]{2}{*}{ iii } & \multirow{2}{*}{$\mathrm{NHCF} / \mathrm{CN} / \mathrm{ZnO} / \mathrm{Li} \mid \mathrm{Li}$} & 1 & \multirow[b]{2}{*}{1} & 1050 & 25 & \multirow{2}{*}{$\begin{array}{l}\text { This } \\
\text { work }\end{array}$} \\
\hline & & 2 & & 1100 & 24.2 & \\
\hline \multirow[b]{2}{*}{ iii } & \multirow{2}{*}{ CC/CNT@Li } & 1 & \multirow{2}{*}{1} & 500 & 18 & \multirow[b]{2}{*}[1]{} \\
\hline & & 2 & & 500 & 23 & \\
\hline ii & CNF-TiN@Li & 1 & 1 & 600 & 30 & {$[2]$} \\
\hline $\mathrm{i}$ & CNT@POF Li host & 1 & 1 & 450 & 50 & {$[3]$} \\
\hline ii & $\mathrm{CF} / \mathrm{Ag}-\mathrm{Li}$ & 1 & 1 & 200 & 60 & {$[4]$} \\
\hline ii & 3D-HCFs@Li & 2 & 1 & 600 & 20 & {$[5]$} \\
\hline iii & LZNF@Li & 1 & 1 & 400 & 20 & {$[6]$} \\
\hline iii & CAZPZ-Li & 1 & 1 & 600 & 25 & {$[7]$} \\
\hline iii & CC@CN-Co@Li & 2 & 1 & 800 & 18 & {$[8]$} \\
\hline ii & $\begin{array}{c}\mathrm{Mg}_{3} \mathrm{~N}_{2} \text {-containing } \\
\mathrm{CP}\end{array}$ & 1 & 1 & 300 & 25 & {$[9]$} \\
\hline \multirow[b]{2}{*}{$\mathrm{i}$} & \multirow{2}{*}{$\mathrm{Li} 4.4 \mathrm{Sn} / \mathrm{SG}$} & 0.5 & \multirow{2}{*}{1} & 1000 & $\sim 18$ & \multirow{2}{*}[10]{} \\
\hline & & 1 & & 600 & 34 & \\
\hline \multirow[b]{2}{*}{ iii } & \multirow[b]{2}{*}{$\mathrm{TiC} / \mathrm{C} / \mathrm{Li}$} & 0.5 & \multirow{2}{*}{1} & 200 & 20 & \multirow{2}{*}{ [11] } \\
\hline & & 1 & & 200 & 42 & \\
\hline iii & $\mathrm{Li}-(\mathrm{VA}-\mathrm{CuO}-\mathrm{Cu})$ & 0.5 & 0.5 & 700 & - & {$[12]$} \\
\hline \multirow[b]{2}{*}{ iii } & \multirow{2}{*}{ CONF-Li } & 1 & \multirow{2}{*}{1} & 266.7 & \multirow{2}{*}{-} & \multirow{2}{*}{ [13] } \\
\hline & & 2 & & 166.7 & & \\
\hline ii & NGCS@Li & 0.5 & 0.5 & 320 & - & {$[14]$} \\
\hline
\end{tabular}


Table S3 Comparison of electrochemical performance of full cells

\begin{tabular}{|c|c|c|c|c|c|c|c|}
\hline $\begin{array}{l}\text { structure } \\
\text { type of } \\
\text { current } \\
\text { collector }\end{array}$ & Full cell & $\begin{array}{c}\text { Current } \\
\text { rate }\end{array}$ & $\begin{array}{c}\text { Initial } \\
\text { capacity } \\
\left(\mathrm{mAh} \mathrm{g}^{-1}\right)\end{array}$ & $\begin{array}{l}\text { Cycle } \\
\text { number }\end{array}$ & $\begin{array}{c}\text { Capacity } \\
\text { retention } \\
(\%)\end{array}$ & $\begin{array}{c}\text { Coulombic } \\
\text { efficiency } \\
(\%)\end{array}$ & Reference \\
\hline iii & $\mathrm{NHCF} / \mathrm{CN} / \mathrm{ZnO} / \mathrm{Li} \mid \mathrm{Li}$ & $0.5 \mathrm{C}$ & 153 & 500 & 94.77 & 99.52 & This work \\
\hline iii & $\mathrm{Li} / \mathrm{VA}-\mathrm{CuO}-\mathrm{Cu} \mid \mathrm{LFP}$ & $0.5 \mathrm{C}$ & - & 300 & 81.2 & 99.5 & {$[12]$} \\
\hline ii & Li/CuNW-P|LFP & $0.5 \mathrm{C}$ & - & 300 & - & 98.8 & {$[15]$} \\
\hline ii & CI-anode $\mid$ LFP & $1 \mathrm{C}$ & 124 & 100 & 80.1 & - & {$[3]$} \\
\hline ii & Li-CC@ZnO/LiFePO4 & 0.5 & 142 & 300 & 82.5 & - & [16] \\
\hline ii & Li-LCNF@LNafion & 0.5 & - & 120 & - & - & [17] \\
\hline \multirow[b]{2}{*}{ ii } & \multirow{2}{*}{ 3D-HCFs@Li } & 0.2 & - & 150 & 94.4 & - & \multirow{2}{*}[5]{} \\
\hline & & 0.5 & - & 200 & 91.3 & - & \\
\hline ii & P-Cu@Li//LFP & 0.5 & 146.9 & 330 & 87.07 & - & {$[18]$} \\
\hline ii & Li@NCNF|LFP & 0.5 & 148.54 & 300 & 82.4 & - & [19] \\
\hline ii & $\mathrm{LiFePO}_{4} \mid 3 \mathrm{D}$ porous $\mathrm{Cu}$ & 0.5 & 137.5 & 150 & 80 & 98 & [20] \\
\hline iii & Li-NC/CukLFP & 0.1 & 146.9 & 170 & 75.4 & 98.5 & {$[21]$} \\
\hline ii & $\begin{array}{c}\text { N-doped } \\
\text { graphene-Li }|| \mathrm{LiFePO}_{4}\end{array}$ & 0.2 & 156.1 & 500 & 87.8 & - & [22] \\
\hline
\end{tabular}




\section{References}

1. Liu, F.; Xu, R.; Hu, Z.; Ye, S.; Zeng, S.; Yao, Y.; Li, S.; Yu, Y., Regulating Lithium Nucleation via CNTs Modifying Carbon Cloth Film for Stable Li Metal Anode. Small 2019, 15, e1803734.

2. Lin, K.; Qin, X.; Liu, M.; Xu, X.; Liang, G.; Wu, J.; Kang, F.; Chen, G.; Li, B., Ultrafine Titanium Nitride Sheath Decorated Carbon Nanofiber Network Enabling Stable Lithium Metal Anodes. Adv. Funct. Mater. 2019, 29, 1903229.

3. Chen, X. R.; Li, B. Q.; Zhu, C.; Zhang, R.; Cheng, X. B.; Huang, J. Q.; Zhang, Q., A Coaxial Interweaved Hybrid Lithium Metal Anode for Long - Lifespan Lithium Metal Batteries. Adv. Energy Mater. 2019, 9, 1901932.

4. Zhang, R.; Chen, X.; Shen, X.; Zhang, X.-Q.; Chen, X.-R.; Cheng, X.-B.; Yan, C.; Zhao, C.-Z.; Zhang, Q., Coralloid Carbon Fiber-Based Composite Lithium Anode for Robust Lithium Metal Batteries. Joule 2018, 2, 764-777.

5. Liu, L.; Yin, Y.-X.; Li, J.-Y.; Li, N.-W.; Zeng, X.-X.; Ye, H.; Guo, Y.-G.; Wan, L.-J., Free-Standing Hollow Carbon Fibers as High-Capacity Containers for Stable Lithium Metal Anodes. Joule 2017, 1 (3), 563-575.

6. Zhao, F.; Zhou, X.; Deng, W.; Liu, Z., Entrapping Lithium Deposition in Lithiophilic Reservoir Constructed by Vertically Aligned ZnO Nanosheets for Dendrite-Free Li Metal Anodes. Nano Energy 2019, 62, 55-63.

7. Zheng, H.; Zhang, Q.; Chen, Q.; Xu, W.; Xie, Q.; Cai, Y.; Ma, Y.; Qiao, Z.; Luo, Q.; Lin, J.; Wang, L.; Qu, B.; Sa, B.; Peng, D.-L., 3D Lithiophilic-Lithiophobic-Lithiophilic Dual-Gradient Porous Skeleton for Highly Stable Lithium Metal Anode. J. Mater. Chem. A. 2020, 8, 313-322.

8. Zhou, T.; Shen, J.; Wang, Z.; Liu, J.; Hu, R.; Ouyang, L.; Feng, Y.; Liu, H.; Yu, Y.; Zhu, M., Regulating Lithium Nucleation and Deposition via MOF - Derived Co@C - Modified Carbon Cloth for Stable Li Metal Anode. Adv Funct. Mater. 2020, 30, 1909159.

9. Dong, Q.; Hong, B.; Fan, H.; Jiang, H.; Zhang, K.; Lai, Y., Inducing the Formation of In Situ $\mathrm{Li}_{3} \mathrm{~N}$-Rich SEI via Nanocomposite Plating of $\mathrm{Mg}_{3} \mathrm{~N}_{2}$ with Lithium Enables High-Performance 3D Lithium-Metal Batteries. ACS Appl. Mater. Interfaces 2020, 12, 627-636.

10. Jiang, Y.; Jiang, J.; Wang, Z.; Han, M.; Liu, X.; Yi, J.; Zhao, B.; Sun, X.; Zhang, J., Li ${ }_{4.4} \mathrm{Sn}$ Encapsulated in Hollow Graphene Spheres for Stable Li Metal Anodes without Dendrite Formation for Long Cycle-Life of Lithium Batteries. Nano Energy 2020, 70, 104504.

11. Liu, S.; Xia, X.; Zhong, Y.; Deng, S.; Yao, Z.; Zhang, L.; Cheng, X.-B.; Wang, X.; Zhang, Q.; Tu, J., 3D TiC/C Core/Shell Nanowire Skeleton for Dendrite-Free and Long-Life Lithium Metal Anode. Adv. Energy Mater. 2018, 8, 1702322.

12. Zhang, C.; Lv, W.; Zhou, G.; Huang, Z.; Zhang, Y.; Lyu, R.; Wu, H.; Yun, Q.; Kang, F.; Yang, Q.-H., Vertically Aligned Lithiophilic $\mathrm{CuO}$ Nanosheets on a $\mathrm{Cu}$ Collector to Stabilize Lithium Deposition for Lithium Metal Batteries. Adv. Energy Mater. 2018, 8, 1703404.

13. Yue, X.-Y.; Wang, W.-W.; Wang, Q.-C.; Meng, J.-K.; Zhang, Z.-Q.; Wu, X.-J.; Yang, X.-Q.; Zhou, Y.-N., CoO Nanofiber Decorated Nickel Foams as Lithium Dendrite Suppressing Host Skeletons for High Energy Lithium Metal Batteries. Energy Storage Mater. 2018, 14, 335-344.

14. Hou, G.; Ren, X.; Ma, X.; Zhang, L.; Zhai, W.; Ai, Q.; Xu, X.; Zhang, L.; Si, P.; Feng, J.; Ding, F.; Ci, L., Dendrite-Free Li Metal Anode Enabled by a 3D Free-Standing Lithiophilic Nitrogen-Enriched Carbon Sponge. J. Power Sources 2018, 386, 77-84.

15. Zhang, C.; Lyu, R.; Lv, W.; Li, H.; Jiang, W.; Li, J.; Gu, S.; Zhou, G.; Huang, Z.; Zhang, Y.; Wu, J.; Yang, Q. H.; Kang, F., A Lightweight 3D Cu Nanowire Network with Phosphidation Gradient as 
Current Collector for High-Density Nucleation and Stable Deposition of Lithium. Adv. Mater. 2019, 31, e1904991.

16. Wang, X.; Pan, Z.; Wu, Y.; Ding, X.; Hong, X.; Xu, G.; Liu, M.; Zhang, Y.; Li, W., Infiltrating Lithium into Carbon Cloth Decorated with Zinc Oxide Arrays for Dendrite-Free Lithium Metal Anode. Nano Research 2018, 12, 525-529.

17. Xiang, J.; Zhao, Y.; Yuan, L.; Chen, C.; Shen, Y.; Hu, F.; Hao, Z.; Liu, J.; Xu, B.; Huang, Y., A Strategy of Selective and Dendrite-Free Lithium Deposition for Lithium Batteries. Nano Energy 2017, $42,262-268$.

18. Wang, L.-M.; Tang, Z.-F.; Lin, J.; He, X.-D.; Chen, C.-S.; Chen, C.-H., A 3D Cu Current Collector with a Biporous Structure Derived by a Phase Inversion Tape Casting Method for Stable Li Metal Anodes. J. Mater. Chem. A. 2019, 7, 17376-17385.

19. Wu, H.; Zhang, Y.; Deng, Y.; Huang, Z.; Zhang, C.; He, Y.-B.; Lv, W.; Yang, Q.-H., A Lightweight Carbon Nanofiber-Based 3D Structured Matrix with High Nitrogen-Doping Level for Lithium Metal Anodes. Sci. China Mater. 2018, 62, 87-94.

20. Shi, Y.; Wang, Z.; Gao, H.; Niu, J.; Ma, W.; Qin, J.; Peng, Z.; Zhang, Z., A Self-Supported, Three-Dimensional Porous Copper Film as a Current Collector for Advanced Lithium Metal Batteries. J. Mater. Chem. A 2019, 7, 1092-1098.

21. Yin, D.; Huang, G.; Wang, S.; Yuan, D.; Wang, X.; Li, Q.; Sun, Q.; Xue, H.; Wang, L.; Ming, J., Free-Standing 3D Nitrogen-Carbon Anchored $\mathrm{Cu}$ Nanorod Arrays: In Situ Derivation from a Metal-Organic Framework and Strategy to Stabilize Lithium Metal Anodes. J. Mater. Chem. A 2020, 8, 1425-1431.

22. Liu, M.; Deng, N.; Ju, J.; Wang, L.; Wang, G.; Ma, Y.; Kang, W.; Yan, J., Silver Nanoparticle-Doped 3D Porous Carbon Nanofibers as Separator Coating for Stable Lithium Metal Anodes. ACS Appl. Mater. Interfaces 2019, 11, 17843-17852. 